\title{
HS-SPME-GC-MS Analysis of onion (Allium cepa L.) and shallot (Allium ascalonicum $\mathbf{L}$.)
}

\author{
*D'Auria, M. and Racioppi, R. \\ Dipartimento di Scienze, Università della Basilicata, Viale dell'Ateneo Lucano 10, 85100 Potenza, Italy
}

\begin{abstract}
Article history:
Received: 19 May 2017

Received in revised form:

15 June 2017

Accepted: 16 June 2017

Available Online: 21 June

2017
\end{abstract}

\section{Keywords:}

Volatile organic compounds Onion

Shallot

Solid phase microextraction

Gas chromatography

Mass spectrometry

DOI:

http://doi.org/10.26656/

fr.2017.5.055

\begin{abstract}
The volatile organic compounds of onion and shallot were determined via HS-SPME-GC -MS. The main components were dipropyldisulphide and allylpropyldisulphide. Thiopropanal S-oxide were detected only in onion volatiles. In shallot is interesting the presence of 2-methyl-2-pentenal, a compound with an intense fruity aroma, that can characterize the different aroma between onion and shallot. The SPME-GC-MS analysis of shallot after absorption on the SPME fiber at $50^{\circ} \mathrm{C}$ showed the presence of new compounds, whose structures have been discussed.
\end{abstract}

\section{Introduction}

Solid Phase MicroExtraction (SPME) has been widely used to determine volatile organic compounds. In our experience in this field, we used this method to determine fire accelerant in fire debris (D'Auria, 2006), volatile organic compounds in crude oil (D'Auria et al., 2009), olive oil (Bentivenga, D'Auria, Fedeli et al., 2004), wine (Acquaviva et al., 2014), saffron (D'Auria et al.,2006), truffles (D'Auria et al., 2014), honey (Bentivenga, D'Auria, Mauriello et al., 2004), horseradish (D'Auria et al., 2004) thymus, rosemary, laurel, sage (D'Auria and Racioppi, 2015), lavender and oregano (D'Auria et al., 2005), kiwi (Celano at al., 2006), Monilinia species (Mang et al., 2015) and in the scent of an orchid (D'Auria et al., 2017).

The analysis of the volatile organic compounds of onions has been the object of several works (Mondy et al., 2001; Auger et al., 2005; Lanzotti 2013). SPME has been used in the analysis of onion (Järvenpää et al., 1998; Mondy et al., 2002; Soto et al., 2015). However, SPME has not been used in the determination of volatile organic compounds of shallot (Allium ascalonicum L.).

In this article, we want to report the SPME analysis of both onion and shallot in order to understand the origin of possible differences in the volatile organic compounds composition.

\section{Materials and methods}

Onion and shallot have been cleaned of the outermost layers and finely cut with a knife. The analysis was carried out immediately after cutting, using approximately two grams for each species.

A $50 / 30-\mu \mathrm{m}$ DVB/CAR/PDMS module (57328-U, Supelco, Milan, Italy) was employed to determine VOCs. SPME fiber was maintained over the sample in a $20 \mathrm{ml}$ vial at $20^{\circ} \mathrm{C}$ et at $40^{\circ} \mathrm{C}$ for $20 \mathrm{~min}$. Analyses were accomplished with an HP 6890 Plus gas chromatograph equipped with a Phenomenex Zebron ZB-5 MS capillary column (30-m x $0.25-\mathrm{mm}$ i.d. x $0.25 \mu \mathrm{m}$ FT) (Agilent, Milan, Italy). An HP 5973 mass selective detector (Agilent) was utilized with helium at $0.8 \mathrm{ml} / \mathrm{min}$ as the carrier gas. A splitless injector was maintained at $250^{\circ} \mathrm{C}$ and the detector at $230^{\circ} \mathrm{C}$. The oven was held at $40^{\circ} \mathrm{C}$ for $2 \mathrm{~min}$, then gradually warmed, $8^{\circ} \mathrm{C} / \mathrm{min}$, up to $250^{\circ} \mathrm{C}$ and held for $10 \mathrm{~min}$. Tentatively identification of aroma 
components was based on mass spectra and Wiley 6 and NITS 98 library comparison. Single VOC peak was considered as identified when its experimental spectrum matched with a score over $90 \%$ that present in the library. The Kovats Retention Index was used to identify the aroma components (Kovats, 1958). All the analyses were performed in triplicate.

\section{Results and discussion}

The origin of sulfur-containing compounds in onions has been extensively studied in the past (Block, 1992). They originate from $S$-alkyl or $S$-alkenyl-L-cysteine- $S$ oxide (1), present in the cytoplasm, when they react with alliinase, located in the vacuoles. The reaction allowed the formation of the corresponding sulfenic acids $\mathbf{2}$, that was converted into the corresponding thiosulfinates 3 (Figure 1). This type of compounds are not stable and was converted in several derivatives, some of them are reported in Figure 1). In onions, a relative importance was attributed to the propanethial $S$-oxide, a lachrymatory factor found in onions.

We performed the analysis of both onion (Allium cepa L.) and shallot (Allium ascalonicum L.) by absorption of volatiles in sliced samples at $20{ }^{\circ} \mathrm{C}$. The use of this temperature has been due to the need to avoid rapid decomposition of the lachrymatory agent emitted by onion. The results are reported in Table 1 .

The analysis of onion allowed the identification of ten components. The main components were dipropyldisulphide and allylpropyldisulphide. It is noteworthy that, by using this type of analysis, thiopropanal $S$-oxide, the lachrymatory agent emitted by onions, can be detected. This compound cannot be detected in the analysis of shallot. Also in shallot the main components were dipropyldisulphide and allylpropyldisulphide. It is interesting the presence of 2methyl-2-pentenal, an intense fruity aroma, that can characterize the different aroma between onion and shallot.

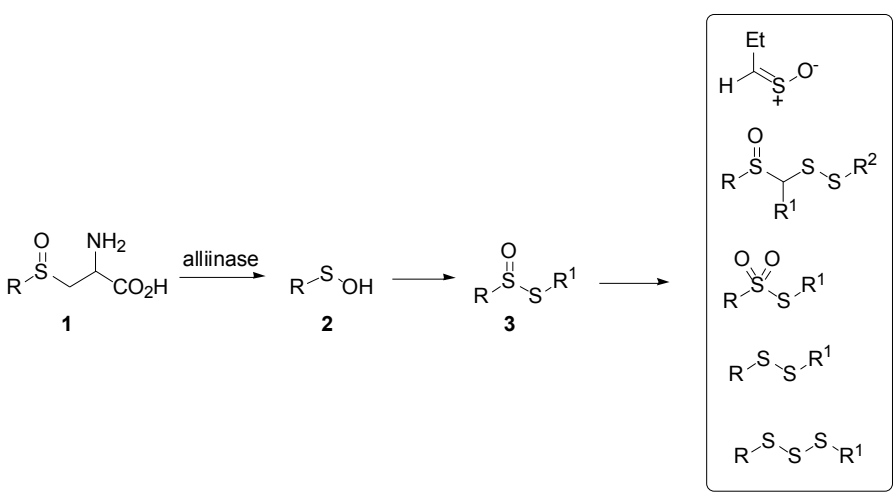

Figure 1. The origin of sulphur compounds in onion.
Table 1. Volatile organic compounds in onion and shallot with absorption on SPME fiber at $20^{\circ} \mathrm{C}$.

\begin{tabular}{|c|c|c|c|c|}
\hline \multirow{2}{*}{ Compound } & \multirow{2}{*}{$\begin{array}{c}\text { r.t. } \\
{[\mathrm{min}]}\end{array}$} & \multirow{2}{*}{$\mathrm{KI}$} & \multicolumn{2}{|c|}{ Area \% } \\
\hline & & & Onion & Shallot \\
\hline Methanethiol & 1.61 & 500 & $\begin{array}{c}3.25 \pm \\
0.02\end{array}$ & $\begin{array}{c}0.46 \pm \\
0.01\end{array}$ \\
\hline Propanethiol & 2.30 & 600 & $\begin{array}{c}2.30 \pm \\
0.01\end{array}$ & $\begin{array}{c}4.20 \pm \\
0.02\end{array}$ \\
\hline Thiopropanal $S$-oxide & 4.37 & 740 & $\begin{array}{c}0.36 \pm \\
0.03\end{array}$ & \\
\hline 2-Methyl-2-pentenal & 5.66 & 804 & & $\begin{array}{c}0.13 \pm \\
0.01\end{array}$ \\
\hline 2,5-Dimethylthiophene & 7.18 & 865 & $\begin{array}{c}2.33 \pm \\
0.01\end{array}$ & $\begin{array}{c}1.06 \pm \\
0.01\end{array}$ \\
\hline $\begin{array}{l}\text { Methylisopropyldisul- } \\
\text { phide }\end{array}$ & 7.78 & 880 & $\begin{array}{c}3.53 \pm \\
0.03\end{array}$ & $\begin{array}{c}2.74 \pm \\
0.02\end{array}$ \\
\hline Dipropyldisulphide & 11.64 & 1094 & $\begin{array}{l}51.41 \\
\pm 0.05\end{array}$ & $\begin{array}{l}58.57 \\
\pm 0.05\end{array}$ \\
\hline Allylpropyldisulphide & 11.82 & 1098 & $\begin{array}{l}20.69 \\
\pm 0.05\end{array}$ & $\begin{array}{r}13.27 \\
\pm 0.05\end{array}$ \\
\hline $\begin{array}{l}\text { Methyl propylthiosul- } \\
\text { fonate }\end{array}$ & 12.35 & 1154 & $\begin{array}{c}0.59 \pm \\
0.01\end{array}$ & $\begin{array}{c}0.46 \pm \\
0.02\end{array}$ \\
\hline Dipropyltrisulphide & 15.52 & 1294 & $\begin{array}{c}4.66 \pm \\
0.02\end{array}$ & $\begin{array}{c}6.99 \pm \\
0.03\end{array}$ \\
\hline Allylpropyltrisulfide & 15.74 & 1309 & $\begin{array}{c}1.31 \pm \\
0.01\end{array}$ & $\begin{array}{c}0.83 \pm \\
0.01\end{array}$ \\
\hline
\end{tabular}

It is noteworthy that in previously published paper on Allium cepa L. and Allium porrum L. 2-methyl-2pentenal was one of the main components found in the analyzed oil (Schulz et al., 1998). Probably, this observed difference depends on the extraction methodology used in the article where an aqueous blend was extracted with pentane for three hours.

Furthermore, it is noteworthy that most of the compounds we found in both onion and shallot did not compare in the list of the compound found in previous SPME study on onion samples (Mondy et al., 2002).

When the absorption of volatile organic compounds was performed at $50^{\circ} \mathrm{C}$ the nature of the compounds found in onion and shallot considerably changed. The results are collected in Table 2. We collected the results only for shallot, in order to see if the increased temperature can change the volatile profile of the species. We observed a neat reduction of the amounts of dipropyl- and allylpropyldisulphide, while the amount of dipropyl and allyldipropyltrisuphide increased. Furthermore, we observed the formation of new compounds, in our knowledge never observed before. 
Table 2. Volatile organic compounds in shallot with absorption on SPME fiber at $50^{\circ} \mathrm{C}$.

\begin{tabular}{lcc}
\hline Compound & r.t. [min] & Area \% \\
\hline Propanethiol & 2.31 & $2.57 \pm 0.01$ \\
2-Methyl-2-pentenal & 5.65 & $0.20 \pm 0.01$ \\
2,5-Dimethylthiophene & 7.18 & $0.51 \pm 0.01$ \\
Methylpropyldisulphide & 7.77 & $1.42 \pm 0.03$ \\
Dipropyldisulphide & 11.62 & $34.80 \pm 0.05$ \\
Allylpropyldisulphide & 11.79 & $7.14 \pm 0.03$ \\
Methylpropylthiosulfonate & 12.36 & $1.72 \pm 0.02$ \\
Dipropyltrisulphide & 15.66 & $21.70 \pm 0.05$ \\
Allylpropyltrisulphide & 15.82 & $9.18 \pm 0.03$ \\
Compound 4 & 19.41 & $4.35 \pm 0.03$ \\
Compound 5 & 19.64 & $2.00 \pm 0.02$ \\
Compound 6 & 19.80 & $3.72 \pm 0.02$ \\
Compound 7 & 22.51 & $2.02 \pm 0.02$ \\
\hline
\end{tabular}

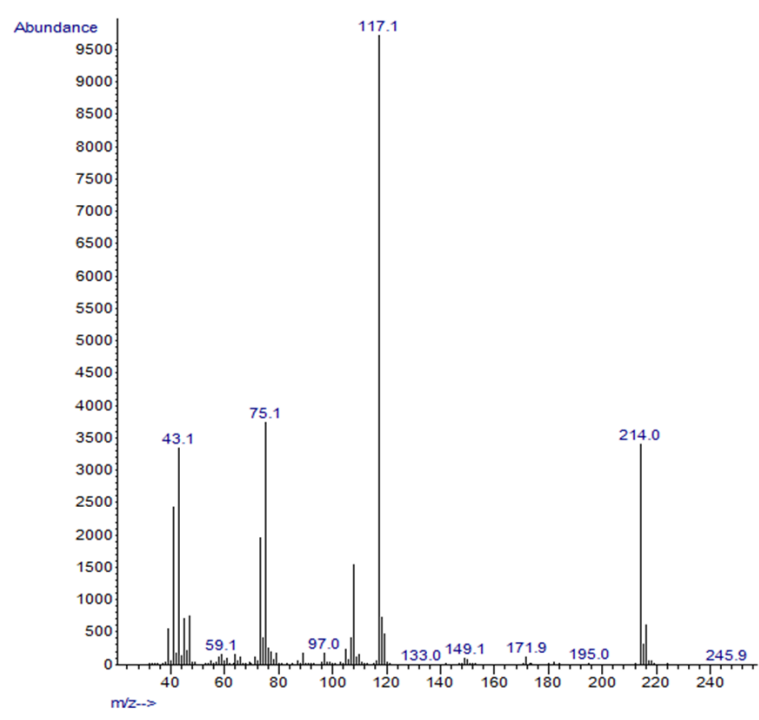

Figure 2. Mass spectrum of compound 4.

Figure 2 showed the mass spectrum registered for the compound 4 found at $19.41 \mathrm{~min}$. The molecular peak showed a very small abundance and can be found at $\mathrm{m} / \mathrm{z}$ 214. The analysis of the relative abundance of the isotopic peak at $\mathrm{m} / \mathrm{z} 216$ showed that this molecule contained four sulfur atoms. The peak at $\mathrm{m} / \mathrm{z} 117 \mathrm{can}$ be in agreement with $\mathrm{CH}_{3} \mathrm{CH}_{2} \mathrm{CH}_{2} \mathrm{SCH}_{2} \mathrm{CH}_{2} \mathrm{CH}_{2}{ }^{+}$ion. The assignment is in agreement also with the fragment at $\mathrm{m} / \mathrm{z}$ $43\left(\mathrm{CH}_{3} \mathrm{CH}_{2} \mathrm{CH}_{2}^{+}\right)$and that at $\mathrm{m} / z 75\left(\mathrm{CH}_{3} \mathrm{CH}_{2} \mathrm{CH}_{2} \mathrm{~S}^{+}\right)$. On the basis of this assignment, the fragment at $\mathrm{m} / z 214$ can be identified as $\left(\mathrm{CH}_{3} \mathrm{CH}_{2} \mathrm{CH}_{2} \mathrm{SCH}_{2} \mathrm{CH}_{2} \mathrm{CH}_{2} \mathrm{SSSH}\right)^{+}$. The compound $\mathbf{4}$ can be tentatively identified as described in Figure 3 as 3-(propanethiyl)propanetrithiol.
The compound $\mathbf{5}$, found after $19.64 \mathrm{~min}$ in our gaschromatographic analysis, shown the mass spectrum reported in Figure 4. The spectrum did not show the molecular peak. The fragment at $m / z 115$ is in agreement with the presence of the structure $\mathrm{CH}_{3} \mathrm{CH}_{2} \mathrm{CH}_{2} \mathrm{SCH}=\mathrm{CH}$ $\mathrm{CH}_{2}{ }^{+}$. The presence of a stabilized allylic carbocation can account for the absence due to the loss of sulfur. The proposed structure is shown in the Figure 3 as 3(propanethiyl)-2-propenetrithiol. The compound found at $19.80 \mathrm{~min}$ in the gas-chromatogram showed a molecular peak at $m / z 212$ (Figure 5). The fragment at $m / z 147$ is due to the loss of SSH, while the fragment at $\mathrm{m} / z 115$, can be due to the loss of SSSH from the molecular peak. The mass is in agreement with the structure $\mathrm{CH}_{2}=\mathrm{CHCH}_{2} \mathrm{SCH}_{2} \mathrm{CH}_{2} \mathrm{CH}_{2}{ }^{+}$. The proposed structure for the compound 6 is shown in Figure 3 as 3-(2propenethiyl)-propanetrithiol.

The compound 7, found at $22.51 \mathrm{~min}$, showed the mass spectrum reported in Figure 6. The molecular peak was not present in the spectrum. The main fragmentation

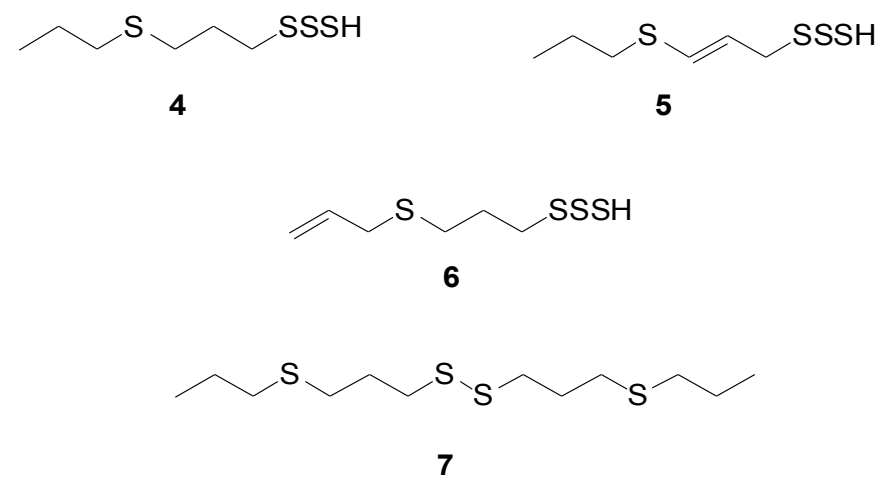

Figure 3. Proposed structures for compounds 4-7

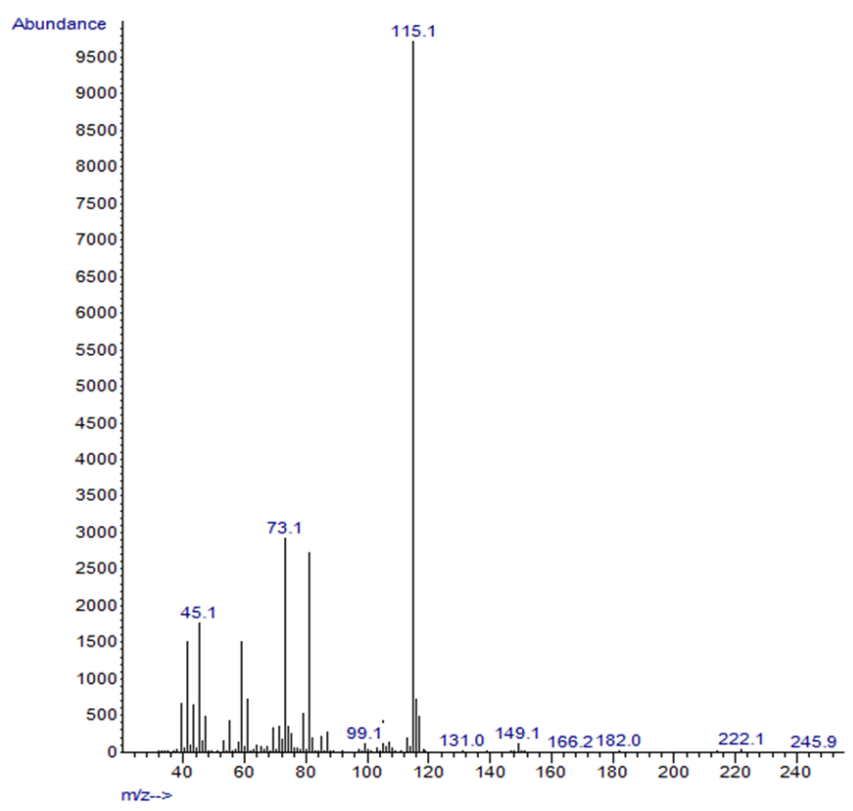

Figure 4. Mass spectrum of compound $\mathbf{5}$ 
at $\mathrm{m} / \mathrm{z} 149$ is in agreement with a dimeric structure 7 (Figure 3) as 3,3'-di(propanethiyl)dipropyldisulphide.

In conclusion, we have shown that SPME can be used in order to characterize the volatile organic compounds emitted by sliced onions and shallots. We observed some differences between these two species attributable to the organoleptic differences between the species. In fact, it is well known that shallot has less intense, more aromatic and slightly garlicky smell.

Furthermore, the analysis obtained through absorption on the SPME fiber at higher temperature allowed to isolate new compounds.

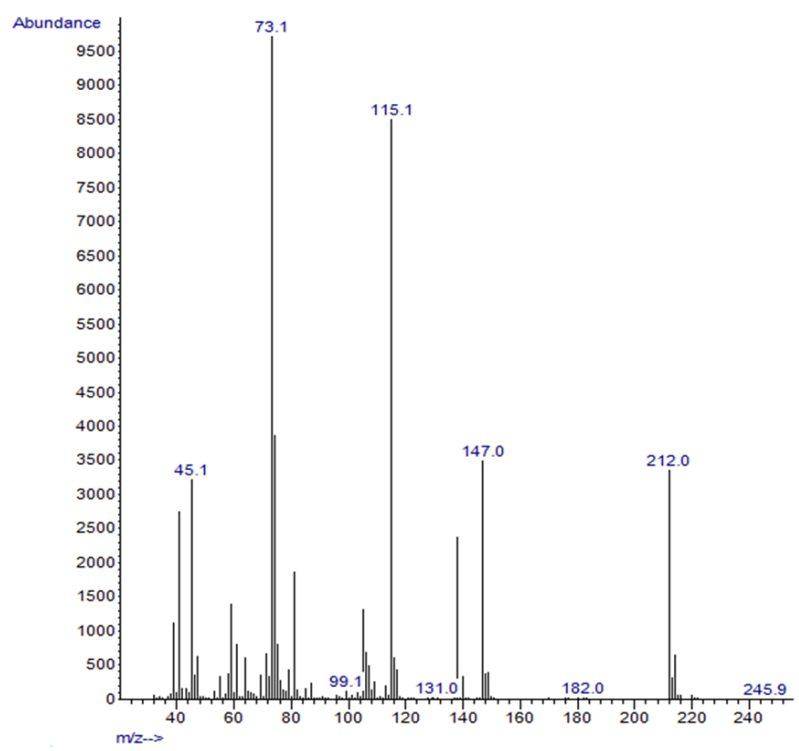

Figure 5. Mass spectrum of compound 6

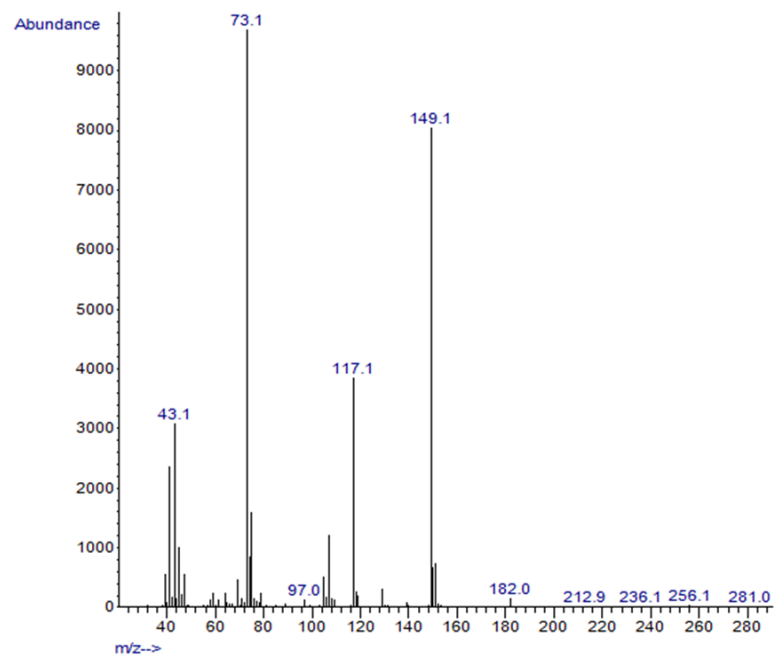

Figure 6. Mass spectrum of compound 7

\section{References}

Acquaviva, V., D'Auria, M. and Racioppi R. (2014). Changes in aliphatic ester composition in white wines during exposition to light. An HS-SPME-GCMS study. Journal of Wine Research, 25, 63-74.

Auger, J., Arnault, I., Legin, A., Rudnitskaya, A., Seleznev, B., Sparfel, G. and Doré C. (2005) Comparison of gas-chromatography-mass spectrometry and electronic tongue analysis for the classification of onions and shallots. International Journal of Environmental Analytical Chemistry, 85, 971-980.

Bentivenga, G., D’Auria, M., Fedeli, P., Mauriello, G. and Racioppi R. (2004b). SPME-GC-MS analysis of volatile organic compounds in honey from Basilicata. Evidence for the presence of pollutants from anthropogenic activities. International Journal of Food Science and Technology, 39, 1079-1086.

Bentivenga, G., D’Auria, M., Mauriello, G., Racioppi, R. and Viggiani, L. (2004a). Characterization of virgin olive oils from Basilicata by using ${ }^{1} \mathrm{H}-\mathrm{NMR}$ and SPME-GC-MS. Rivista Italiana delle Sostanze Grasse, 81, 86-89.

Celano, G., D’Auria, M., Xiloyannis, C., Mauriello, G. and Baldassarre, M. (2006). Composition and seasonal variation of soluble cuticolar waxes in Actinidia deliciosa leaves. Natural Product Research, 20, 701-709.

D'Auria, M., Emanuele, L., Racioppi, R. and Velluzzi, V. (2009). Photochemical degradation of crude oil: comparison between direct irradiation, photocatalysis, and photocatalysis on zeolite. Journal of Hazardous Materials, 164, 32-38.

D’Auria, M., Lorenz, R., Racioppi, R. and Romano, V.A. (2017). Fragrance components of Platanthera bifolia subsp. osca. Natural Product Research, 31 (14), 1612-1619. doi:10.1080/14786419.2017.1289203.

D'Auria, M., Mauriello, G. and Racioppi, R. (2004). SPME-GC-MS analysis of horseradish (Armoracia rusticana). Italian Journal of Food Science, 16, 501504.

D’Auria, M., Mauriello, G., Marino, R. and Racioppi, R. (2005). Composition of volatile fraction from Thymus, Origanum, Lavandula and Acinos species. Journal of Essential Oil Bearing Plants, 8, 36-51.

D'Auria, M., Mauriello, G., Racioppi, R. and Rana, G.L. (2006). Use of SPME-GC-MS in the study of time evolution of the constituents of saffron aroma: modifications of the composition during storage. Journal of Chromatographic Science, 44, 18-21.

D'Auria, M. (2006). Determination of volatile organic compounds, p. 175-208. Roma: Aracne. 
D'Auria, M. and Racioppi, R. (2015). The effect of drying on the composition of volatile organic compounds in Rosmarimuns officinalis, Laurus nobilis, Salvia officinalis and Thymus serpyllum. A HS-SPME-GC-MS study. Journal of Essential Oil Bearing Plants, 18, 1209-1223.

D'Auria, M., Racioppi, R., Rana, G.L. and Laurita, A. (2014). Studies on volatile organic compounds of some truffles and false truffles. Natural Product Research, 28, 1709-1717.

Järvenpää, E.P., Zhang, Z., Huopalahti, R. and King, J.W. (1998). Determination of fresh onion (Allium cepa L.) volatiles by solid phase microextraction combined with gas chromatography-mass spectrometry. Zeitschrift für LebensmittelUntersuchung und -Forschung A, 207, 39-43.

Lanzotti, V. (2013). The analysis of onion and garlic. Journal of Chromatography A, 1112, 3-22.

Mang, S.M., Racioppi, R., Camele, I., Rana, G.L. and D'Auria, M. (2015). Use of volatile metabolite profiles to distinguish three Monilinia species. Journal of Plant Pathology, 97, 55-59.

Mondy, N., Duplat, D., Christides, J.P., Arnault, I. and Auger, J. (2002). Aroma analysis of fresh and preserved onions and leek bt dual solid-phase microextraction-liquid extraction and gas chromatography-mass spectrometry. Journal of Chromatography A, 963, 89-93.

Mondy, N., Naudin, A., Christides, J.P., Mandon, N. and Auger, J. (2001). Comparison of GC-MS and HPLC for the analysis of Allium volatiles. Chromatographia, 53, S356-S360.

Schulz, H., Krüger, H., Liebmann, J. and Peterka, H. (1998). Distribution of volatile sulfur compounds in an interspecific hybrid between onion (Allium cepa L.) and leek (Allium porrum L.). Journal of Agricultural and Food Chemistry, 46, 5220-5224.

Soto, V.C., Maldonado, I.B., Jofré, VP., Galmarini, C.R. and Silva, M.F. (2015). Direct analysis of nectar and floral volatile organic compounds in hybrid onions by HS-SPME/GC-MS: relationship with pollination an seed production. Microchemical Journal, 122, 110-118. 